\title{
Antifungal activity of Streptomyces longisporoflavus isolated from Lonar Lake against Alternaria solani
}

\author{
H. J. Bhosale. ${ }^{1}$, S. Raut. ${ }^{2}$, T. A. Kadam ${ }^{3}$ \\ ${ }^{1,2,3}$ School of Life Sciences, SRTM University, Nanded-431606, Maharashtra, India \\ *Corresponding Author: bhoslehemlata@gmail.com
}

Available online at: www.isroset.org

Received: 19/May/2018, Revised: 28/May/2018, Accepted: 22/Jun/2018, Online: 30/Jun/ 2018

\begin{abstract}
Actinomycetes were isolated from water samples of Lonar Lake, Buldhana district of Maharashtra, India and screened for their antifungal activity by agar well diffusion method against phyto-pathogenic fungus Alternaria solani. The strain LL-5 showing highest antifungal activity was identified as Streptomyces longisporoflavus on the basis of microscopic and biochemical characteristics. The antifungal metabolite production using S. longisporoflavus was optimized based on optimal incubation period, temperature, initial $\mathrm{pH}$ of medium and supplementation of carbon and nitrogen sources. The study revealed that incubation period of 8 days, $30^{\circ} \mathrm{C}, \mathrm{pH} 10.0$, starch $(1 \%)$ as carbon source and peptone $(0.5 \%)$ as nitrogen source are favorable parameters for maximum production of antifungal metabolite by $S$. longisporoflavus. These results clearly elucidates that $S$. longisporoflavus isolated from Lonar Lake water sample could be a good source of antifungal metabolite that can be used for management of diseases caused by Alternaria solani.
\end{abstract}

Keywords: Antifungal activity, Alternaria solani, Lonar Lake, Streptomycetes, disease management.

\section{INTRODUCTION}

Fungal phyto-pathogens pose serious complications worldwide in the cultivation of economically important crops due to the plant diseases caused by them. Plant diseases caused by fungi include rusts, smuts, rots, and may cause severe damage to crops. Chemical fungicides are extensively used in current agriculture to control fungal pathogens. However, the extensive use of chemical fungicides in agriculture is associated with deleterious effects on human health, environmental pollution and development of pathogen resistance to fungicides.

'Alternaria solani is a fungal pathogen causing early blight disease in tomato and potato plants growing in tropical and subtropical regions. The pathogen produces leaf spots, stem lesions and fruit rot on tomato and tuber blight on potato plants. The yield loss increase by $1.36 \%$ with every $1 \%$ increase in disease intensity and in severe conditions complete crop failure can occur [1]. A. solani is one of the most important foliar pathogens of potato which results in decreased tuber quality and yield reduction of 20$30 \%$. It can cause dry rot of tubers and may also reduce storage length that affects the quantity and quality of marketable tubers[2].

Recent disease management practices include cultural practices, use of resistant cultivars and chemical control. The maintenance of adequate soil fertility levels is critical for managing early blight caused by A. solani. At the same time, complete resistance to early blight does not exist in commercial potato or tomato cultivars. Hence, most often farmers are adopting chemical control methods based on the use of fungicides for disease management. The most common and cheaper protectant fungicides are mancozeb and chlorothalonil. However, their limitations include need to apply regularly and relative high use rates and emerging reduced sensitivity to these protectants [3]. Due to increased public concern about the development of resistance among conventional fungicides and pesticides and the accumulation of their residues in biosphere, development of alternative strategies for plant disease suppression is an area of interest for academicians and researchers.

Actinomycetes are gram positive filamentous organisms commonly isolated from diverse environments and are one of the important natural sources used for isolation of large number of bioactive compounds including antibacterials, antifungals, enzyme suppressors, anticancer agents, immunomodulators, antioxidants and antivirals. Many of these secondary metabolites are produced by Streptomyces species that made Streptomycetes as primary antibiotic producers. Actinomycetes are widely distributed in soil, water and other natural environments and their population and activity get affected by physicochemical and 
biological properties of the ecosystem. In the present study, actinomycetes isolated from Lonar Lake are used for screening their antifungal potential against $A$. solani. This lake is situated in Buldhana district of Maharashtra and uniquely formed be meteorite impact in basalt rock. The lake water is having alkaline $\mathrm{pH}$ and high salinity. Hence, organisms growing in this environment are expected to show unique biochemical activities.

Keeping in view the need for safe, ecofriendly and effective aspects for management of $A$. solani caused diseases, the present study is planned to isolate and screen actinomycetes from Lonar lake water for antifungal activity against $A$. solani, identify the efficient strain and study some parameters affecting the antifungal activity of selected strain. Rest of the paper is organized with different sections, section I contains the brief introduction about the pathogenesis of $A$ solani, limitations of existing disease management practices and importance of actinomycetes as biocontrol agents, Section II includes experimental design followed, Section III describes results and discussion and Section IV concludes research work with future directions.

\section{MATERIALS AND METHODS}

\section{Collection of water sample}

The water sample was collected from different sites of Lonar lake and individual samples were mixed to obtain a composite sample in sterile polythene bags. The samples were stored at $4^{\circ} \mathrm{C}$ till further use.

\section{Isolation of actinomycetes}

The $0.1 \mathrm{ml}$ of water sample was spread on sterile starch casein agar plates supplemented with amphoterecin B $(30 \mu \mathrm{g} / \mathrm{ml})$ and chloramphenicol $(30 \mu \mathrm{g} / \mathrm{ml})$. the plates were incubated at $28 \pm 2{ }^{\circ} \mathrm{C}$ for $7-10$ days. Six well isolated and morphologically distinct colonies of actinomycetes (LL1, LL2, LL3, LL4, LL5 and LL6) were selected and transferred on sterile starch casein agar slants and the well grown culture on slants were stored at $4^{\circ} \mathrm{C}$ till further use.

\section{Preparation of extracts for testing antifungal activity}

The selected isolates of actinomycetes were inoculated individually in sterile $100 \mathrm{ml}$ Erlenmeyer flasks containing $50 \mathrm{ml}$ sterile starch casein broth. Each flask was then incubated at $28 \pm 2{ }^{\circ} \mathrm{C}$ for seven days in an orbital shaking incubator rotating at $120 \mathrm{rpm}$. After incubation, the culture flasks were centrifuged at $10,000 \mathrm{rpm}$ for $20 \mathrm{~min}$ at $4^{\circ} \mathrm{C}$. The individual cell free extracts were collected and subjected for solvent extraction using ethyl acetate in 1: 1 ratio. The ethyl acetate extracts were collected and evaporated at $40^{\circ} \mathrm{C}$ in hot air oven. The obtained extracts were dissolved in dimethyl sulfoxide and used for checking antifungal potential against Alternaria solani isolated from an infected tomato plants from agricultural field of Nanded. The fungal culture was procured from fungal culture collection facility center, School of Life Sciences, SRTM University, Nanded.

\section{Antifungal activity of extracts}

The culture of $A$. solani was grown in potato dextrose broth for $48 \mathrm{hrs}$ at $28 \pm 2{ }^{\circ} \mathrm{C}$. The active culture of $A$. solani was spread on the surface of sterile potato dextrose agar plates using alcohol sterilized glass spreader. The wells were punctured on the surface of agar medium using alcohol sterilized cork borer and $30 \mu \mathrm{l}$ of individual extract was added separately in wells. The plates were kept for diffusion at $4^{\circ} \mathrm{C}$ for $30 \mathrm{~min}$. After diffusion, the plates were incubated at $28 \pm 2{ }^{\circ} \mathrm{C}$ for $48 \mathrm{hrs}$. The plates were observed for appearance of inhibition zones around the wells after incubation. The diameter of inhibition zone was measured and the isolate whose extract showed highest antifungal activity was selected for further study.

\section{Identification of selected isolate}

The isolate LL-5 showing highest inhibition potential against $A$. solani was selected and identified using standard criteria given in Bergey's Mannual of Determinative Bacteriology [4]. The techniques and biochemical tests performed were cover slip culture technique [5], cell wall analysis [6,7], decomposition of organic compounds including casein, tyrosine, xanthine, hypoxanthine, hippurate, urea and esculin, lysozyme resistance, $\mathrm{H}_{2} \mathrm{~S}$ production, nitrate reduction, melanin production and utilization of carbon sources (1\%, D-glucose, D-xylose, L-arabinose, L-rhamnose, D-galactose, Dmannitol, D-fructose, D-raffinose, inositol and sucrose) and nitrogen sources $(0.5 \%$, valine, cysteine, phenyl alanine, histidine and hydroxyproline).

\section{Effect of cultural and nutritional parameters on antifungal activity of LL-5 \\ Effect of initial pH of medium}

The $\mathrm{pH}$ of starch casein broth was adjusted to 7.0, 8.0, 9.0, 10.0 and 11.0 with $0.1 \mathrm{M} \mathrm{NaOH}$. All flasks were inoculated with active culture of LL-5 and incubated at $28 \pm 2{ }^{\circ} \mathrm{C}$ for seven days. The antifungal activity against $A$. solani was determined as stated earlier.

\section{Effect of temperature}

The flasks containing sterile starch casein broth were inoculated with active culture of LL-5 and kept for incubation at varying degrees of temperature $\left(25^{\circ} \mathrm{C}, 30^{\circ} \mathrm{C}\right.$, $35^{\circ} \mathrm{C}$ and $40^{\circ} \mathrm{C}$ ) for seven days. After incubation, extracts were obtained and tested for antifungal activity as stated earlier.

\section{Effect of carbon sources}

Five sets of starch casein broth media were prepared by replacing starch with corn meal, banana peels, sugarcane molasses, fructose and lactose along with asset of medium in which starch is not replaced at $1 \%$ level. The flasks were inoculated separately with active culture of LL-5. The 
incubation conditions and antifungal study protocol was as mentioned earlier.

\section{Effect of nitrogen sources}

Casein in Starch casein broth was replaced individually with peptone, malt extract, meat extract and beef extract $(3 \mathrm{~g} / \mathrm{L})$ and the flasks were inoculated separately with active culture of LL-5. The incubation conditions and antifungal study protocol was as mentioned earlier.

\section{Effect of incubation period}

The starch casein broth was inoculated with active culture of LL-5 and incubated for 10 days at $28 \pm 2{ }^{\circ} \mathrm{C}$. At every $24 \mathrm{hrs}$ interval, $5 \mathrm{ml}$ of broth was removed and centrifuged at $10,000 \mathrm{rpm}$ at $4^{\circ} \mathrm{C}$. The cell free extracts were obtained and tested for antifungal activity as mentioned previously.

\section{RESULTS AND DISCUSSION}

In the present study, six morphologically distinct actinomycetes were isolated from Lonar lake water sample and screened for antifungal activity against $A$. solani. The most promising isolate LL-5 showing more antifungal activity (Figure 1a) than other isolates was selected for further studies (Table 1).

The isolate LL-5 was identified to Streptomyces genus on the basis of aerial and substrate mycelia formation and development of spiral chains (Figure 1b). The isolate was gram positive and produced pale white colonies on starch casein agar plates. The whole cell hydrolysate of LL-5 showed the presence of LL-diamino pimelic acid and was without any characteristic sugar indicating type I wall chemotype. Its further characterization was done on the basis of biochemical features (Table 2). On the basis of morphological, chemotypic and biochemical features, the isolate LL-5 was identified as Streptomyces longisporoflavus.

Table 1: Antifungal activity of actinomycetes isolated from Lonar lake against $A$. solani

\begin{tabular}{|l|l|l|}
\hline $\begin{array}{l}\text { Sr. } \\
\text { No. }\end{array}$ & Isolate & $\begin{array}{l}\text { Zone of } \\
\text { inhibition }(\mathbf{m m})\end{array}$ \\
\hline 1. & LL-1 & 00 \\
\hline 2. & LL-2 & 09 \\
\hline 3. & LL-3 & 13 \\
\hline 4. & LL-4 & 11 \\
\hline 5. & LL-5 & 18 \\
\hline 6. & LL-6 & 10 \\
\hline
\end{tabular}

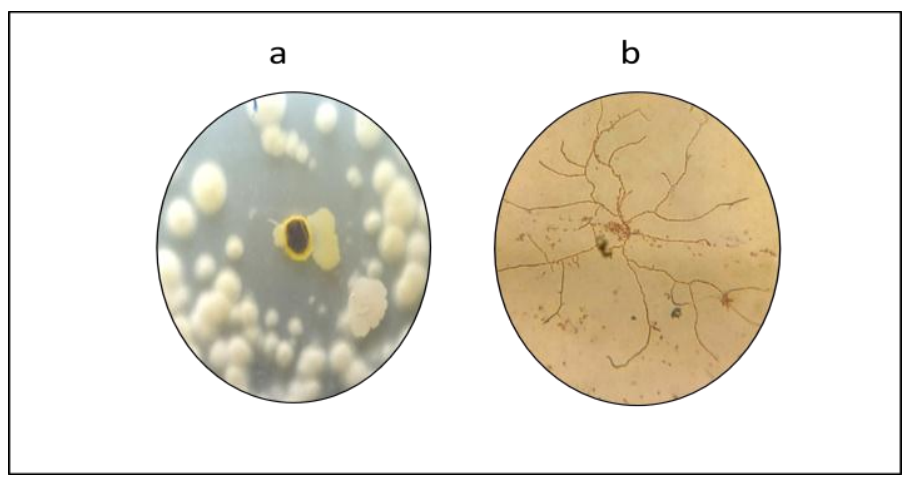

Figure 1a: Antifungal activity of LL-5 strain against A. solani

1b: Light microscopic view of LL-5 strain

Table 2: Morphological and Biochemical characteristics of

\begin{tabular}{|c|c|c|}
\hline \multicolumn{3}{|c|}{ LL-5 isolate } \\
\hline Sr. No. & Test character & Result \\
\hline 1. & Microscopic features & $\begin{array}{l}\text { Aerial mycelium with long } \\
\text { chain of spores }\end{array}$ \\
\hline 2. & Spore mass color & White \\
\hline 3. & Colony reverse & Pale brown \\
\hline 4. & Cell wall chemotype & Type I \\
\hline 5. & $\begin{array}{l}\text { Diagnostic amino acid in whole } \\
\text { cell hydrolysate }\end{array}$ & LL-DAP \\
\hline 6. & $\begin{array}{l}\text { Diagnostic sugar in whole cell } \\
\text { hydrolysate }\end{array}$ & $\begin{array}{l}\text { No Characteristic sugar in } \\
\text { the hydrolysate }\end{array}$ \\
\hline 7. & Melanin production & Negative \\
\hline 8. & Nitrate reduction & Positive \\
\hline 9. & $\mathrm{H} 2 \mathrm{~S}$ production & Negative \\
\hline 10. & $\begin{array}{l}\text { Degradation of } \\
\text { Casein } \\
\text { Hippurate } \\
\text { Esculin } \\
\text { Urea } \\
\text { Hypoxanthine } \\
\text { Tyrosine } \\
\text { Xanthine } \\
\end{array}$ & $\begin{array}{l}\text { Negative } \\
\text { Negative } \\
\text { Positive } \\
\text { Positive } \\
\text { Negative } \\
\text { Positive } \\
\text { Negative }\end{array}$ \\
\hline 11. & $\begin{array}{l}\text { Utilization of carbon sources } \\
\text { Sucrose } \\
\text { Glucose } \\
\text { Galactose } \\
\text { Mannitol } \\
\text { Inositol } \\
\text { Rhamnose } \\
\text { Xylose } \\
\text { Arabinose } \\
\text { Fructose } \\
\text { Salicin } \\
\text { Raffinose } \\
\end{array}$ & $\begin{array}{l}\text { Negative } \\
\text { Negative } \\
\text { Positive } \\
\text { Positive } \\
\text { Positive } \\
\text { Positive } \\
\text { Negative } \\
\text { Negative } \\
\text { Negative } \\
\text { Negative } \\
\text { Positive }\end{array}$ \\
\hline 12. & $\begin{array}{l}\text { Utilization of nitrogen sources } \\
\text { Valine } \\
\text { Cysteine } \\
\text { Phenyl alanine } \\
\text { Histidine } \\
\text { Hydroxyproline }\end{array}$ & $\begin{array}{l}\text { Positive } \\
\text { Negative } \\
\text { Negative } \\
\text { Negative } \\
\text { Positive }\end{array}$ \\
\hline
\end{tabular}

The Streptomycetes are producers of more than half of the 10,000 reported bioactive compounds and have offered a growing interest to industry and academics in last few decades. Gupta et al., [8] isolated Streptomyces 
longisporoflavus from phyllosphere regions of mangrove plants of Kandelia canal whereas Streptomyces longisporoflavus was reported to show antimicrobial activity against $S$. typhi and Candida albicans by Muhsin and Bazzaz [9]. Recently, Arusha et al., [10] reported phosphate solubilizing potential of Streptomyces longisporoflavus AN27 and used it for preparation of biofertilizer in consortium form. However, antifungal activity of Streptomyces longisporoflavus especially against A. solani was not reported earlier.

Streptomyces longisporoflavus LL-5 strain could produce detectable amount of antifungal metabolite in starch casein broth medium. This medium was reported earlier as a good medium for production of antimicrobial metabolites by Streptomyces species [11, 12]. It is necessary to have knowledge on the optimal conditions required for the growth of producer strain and product formation for the development of an efficient fermentation process for the production of secondary metabolites. In the present study, the conditions required for optimal production of antifungal metabolite using Streptomyces longisporoflavus have been optimized using different parameters.

The antifungal activity of LL-5 was observed from the second day of incubation and reached maximum after eighth day in starch casein broth medium. The progressive increase in size of inhibition zone was observed during the first 2-8 days of incubation and decreased gradually thereafter. It is evident from Fig. 2a, the strain produced highest inhibition zone (19 $\mathrm{mm})$ during this incubation period. The decrease in growth of the strain later can be related to the exhaustion of nutrients in media and accumulation of toxic byproducts indicating unfavorable conditions for antifungal compound production. Kathiresan et al [13] optimized the required incubation time for the antifungal effect of the actinomycetes against Fusarium solani and found that it was suppressed with the increase in incubation period. The maximum inhibition was found with cultures incubated for $120 \mathrm{~h}$.

Changes in the initial $\mathrm{pH}$ of the culture medium induce production of new substances that affect antibiotic production [14]. Hence, we examined effect of $\mathrm{pH}$ on antibiotic production by LL-5 and the results are presented in Fig. 2b. The $\mathrm{pH} 10$ was found to be the optimum for antifungal metabolite production $(16 \mathrm{~mm})$. This can be expected as Lonar crater has an alkaline environment with $\mathrm{pH}$ in range of 10-11. The actinomycetes growing here might be adapted to this alkaline environment. Although, we have not examined the alkalophilic nature of LL-5 by growing at alkaline $\mathrm{pH}$, this observed effect indicates that the isolate can grow well at this alkaline $\mathrm{pH}$ and hence showed maximum antibiotic production observed in terms of highest inhibition zone size.

Temperature affects the physiology, morphology, biochemistry and metabolite production by microorganisms and each strain has an optimum temperature requirement at which they grow and produce metabolites maximally. In the present study, Streptomyces longisporoflavus had highest antifungal activity $(17 \mathrm{~mm})$ against $A$. solani at $30{ }^{\circ} \mathrm{C}$ (Fig $2 \mathrm{c})$. This could be expected as most of the actinomycetes isolated from water samples are mesophilic and grow well between $25-30^{\circ} \mathrm{C}$. Similarly, the culture filtrates of antagonistic Streptomycetes are reported to have highest antifungal activity at $30^{\circ} \mathrm{C}$ against Helminthosporium oryzae and Fusarium solani [15] and Fusarium oxysporum [12].
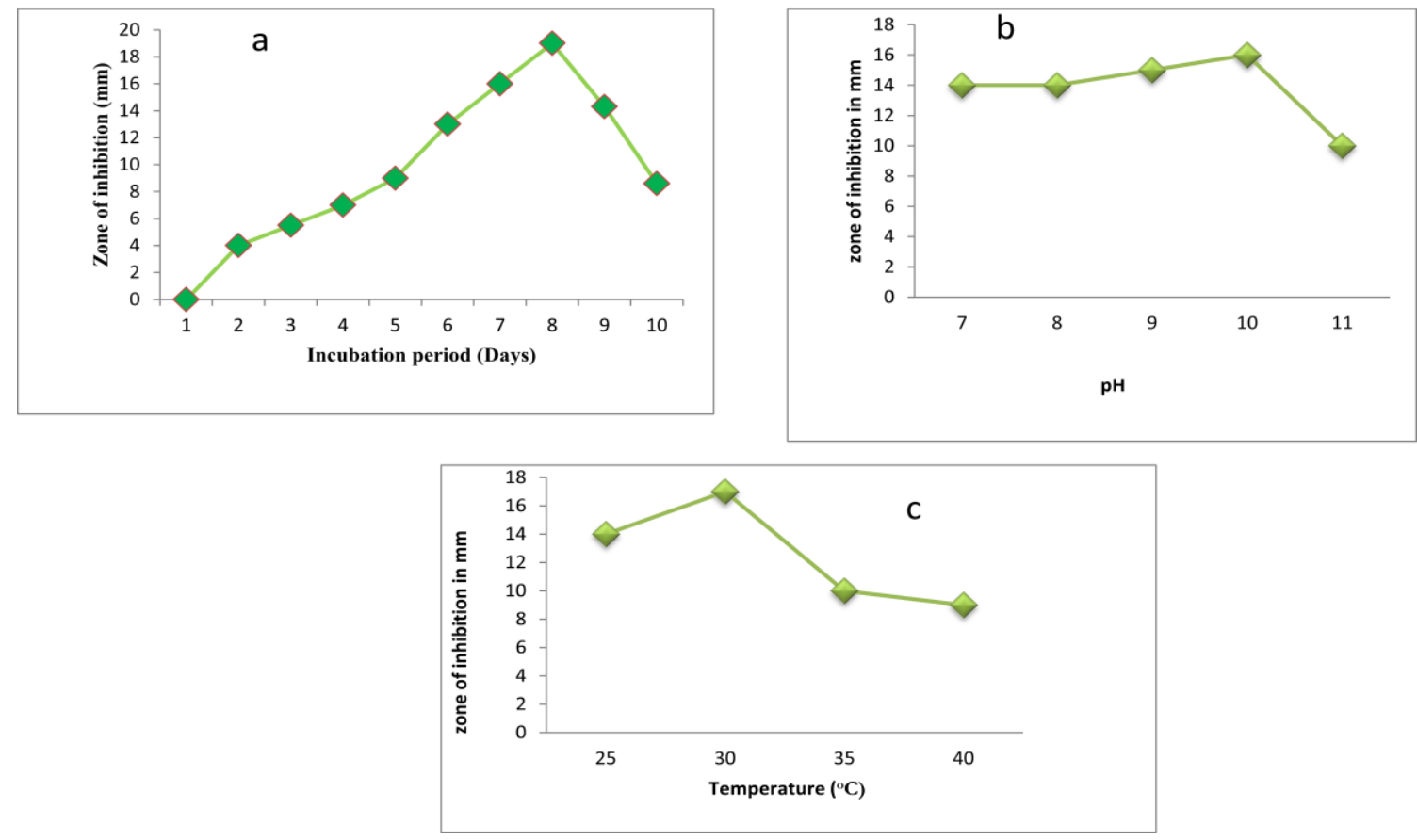

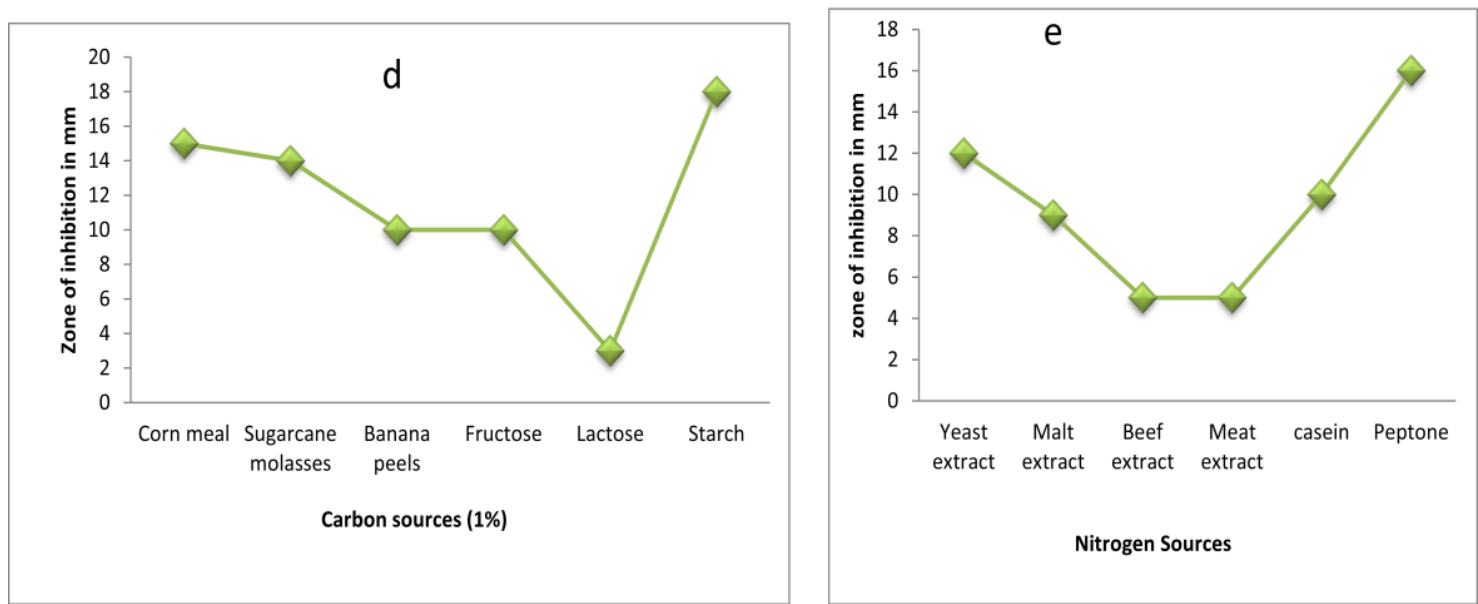

Figure 2: Effect of a. incubation period, b. initial pH of medium, c. temperature, $d$. carbon sources and e. nitrogen sources on antifungal activity of $S$. longisporoflavus LL-5 strain against A. solani.

The effect of carbon sources on antibiotic production by Streptomyces longisporoflavus was measured by measuring size of inhibition zones when the strain was growing on different carbon sources. The strain LL-5 showed maximum antibiotic production in presence of starch while minimal production was found when lactose was present (Fig.2d). Slowly assimilating complex carbon sources like polysaccharides are often known to stimulate secondary metabolite production as these substances do not cause catabolite repression in which production of enzymes required for secondary metabolite biosynthesis are inhibited. Starch is reported earlier to stimulate antibiotic production by actinomycetes $[16$, 17].

Among the nitrogen sources tested, peptone supported maximum antibiotic production by Streptomyces longisporoflavus followed by yeast extract and casein (Fig. 2e). This is in accordance with our previous studies [16] where peptone was found a better source of antifungal metabolite production by a moderately halophilic Streptomyces werraensis $\mathrm{HB}-11$.

\section{CONCLUSION AND FUTURE SCOPE}

Considering the need for new, safe and more effective antifungal antibiotics in agricultural research and significant losses caused by A. solani to vegetable crops, the present study highlighted the biotechnological potential of Streptomyces longisporoflavus in management of $A$. solani caused diseases. Further, the fermentation conditions required for optimal antibiotic production are easily manageable with Streptomyces longisporoflavus which is first time reported here from alkaline Lonar Lake environment. The antifungal metabolite can be produced under optimal conditions, purified and used as a biocontrol agent for management of $A$. solani caused diseases.

\section{REFERENCES}

[1]. K.K. Pandey, P.K. Pandey, G. Kalloo, M.K. Banerjee, "Resistance to early blight of tomato with respect to various parameters of disease epidemics", J. General Pl. Pathol., Vol.69, pp.364-371, 2003.

[2]. M. Olanya, C. Honeycutt, R.P. Larkin, T.S. Griffin, Z. He, J.M. Halloran, "The effect of cropping systems and irrigation management on development of potato early blight". J. Gen. Plant Pathol, Vol.75, pp.267-275, 2009.
[3]. F. Samen, S.J. Goussous, A. Shudifat., I. Makhadmeh, "Reduced sensitivity of tomato early blight pathogen (Alternaria solani) isolates to protectant fungicides and implications on disease control". Archives of phytopathology and plant protection. Vol.49, pp.120-136, 2016.

[4]. J.G. Holt, N.R. Krieg, P.H.A. Sneath, J.T. Staley, S.T. Williams, "Bergey's Manual of Determinative Bacteriology", 9th edn. Baltimore, MD: The Williams and Wilkins Company, 1994.

[5]. B.M. Gibbs, D.A. Shapton DA (eds) (1968). Identification methods for microbiologists, part B, London: Academic press. Pg $111,1968$.

[6]. B. Becker, M.P. Lechevalier, R.E. Gordon, H.A. Lechevalier, "Paper Chromatography of whole-cell hydrolysates", Appl. Microbiol., Vol.12, pp.421-423, 1964.

[7]. M.P. Lechevalier, "Identification of aerobic actinomycetes of clinical importance”. J. Lab. Clin. Med. Vol.71, pp.934-944, 1968.

[8]. N. Gupta N, S. Mishra, U.C. Basak, "Diversity of Streptomyces in mangrove ecosystem of Bhitarkanika", Iranian J Microbiol, Vol.1, pp.37-42, 2009.

[9]. H.E. Muhsin, A.A Bazzaz, "Identification of Streptomyces spp and assessment of their inhibiting metabolic potency against some pathogenic microorganisms". Merit Res J Med. Med Sci, Vol.3, pp.511-516, 2015.

[10]. P.N. Arusha, D.D Karad, S.G. Gupta, A.S. Kharat, "Consortium inoculum of five thermotolerant phosphate solubilizing actinomycetes for multipurpose biofertilizer preparation", Iranian J Microbiol, Vol.9, pp.295-304, 2017.

[11]. R. Vijayakumar, K. Panneerselvam , C. Muthukumar, N. Thajuddin, A. Panneerselvam et al, "Optimization of antimicrobial production by a marine actinomycete Streptomyces afghaniensis VPTS3-1 isolated from Palk Strait, East Coast of India”, Indian J Microbiol., Vol.52, pp.230-239, 2012.

[12]. H.J. Bhosale, T.A. Kadam, R.S. Mirajgave, S.K. Holkar, "Optimization and characterization of antifungal metabolite from a soil actinomycete Streptomyces indiaensis SRT-1". Ind J Biotechnol, 17, 2018 (In press).

[13]. K. Kathiresan, R. Balagurunathan, S.M. Masilamani, "Fungicidal activity of marine actinomycetes against phytopathogenic fungi", Ind J Biotechnol., Vol.4, pp.271-276, 2005.

[14]. S. Omura, A. Nakagawa, H. Yamada, T. Hata, A. Furusaki, T.C. Wtanabe, "Structure and biochemical properties of kanamycin A, $B, C$ and D". Chemical and Pharmaceutical Bulletin, Vol.21, pp. 931-934, 1973. 
[15]. M.K. Gupta, A. Pande, "Effect of physiological and physical factors on antifungal activities of Streptomyces spp". J Ind Bot Soc, Vol.72, pp.157-159, 1992.

[16]. H.J. Bhosale, T.A. Kadam, S.G. Fulwad, M.A. Karale, O.S. Kanse, "Optimization of antifungal compound production by moderately halophilic Str. werraensis HB-11", Int J Pharm Sci Res, Vol.6, pp.1090-99, 2015.

[17]. I.M. Ababutain, Z.K. Abdul Aziz, N.A. Al-Meshhen, "Optimization of environmental and nutritional conditions to improve growth and antibiotic production by Streptomyces sp. isolated from Saudi Arabia soil”. Int Res J Microbiol, Vol.4, pp. 179-187, 2013. 